Tropical Journal of Pharmaceutical Research June 2018; 17 (6): 1019-1024

ISSN: $1596-5996$ (print); 1596-9827 (electronic)

(C) Pharmacotherapy Group, Faculty of Pharmacy, University of Benin, Benin City, 300001 Nigeria.

\title{
Vasodilator effect of 1-trifluoromethoxyphenyl-3-(1- propionylpiperidin-4-yl) urea is predominantly mediated through activation of voltage-dependent $\mathrm{K}+$ channels
}

\author{
Shafiq Ali Shah ${ }^{1,2}$, Malik Hassan Mehmood ${ }^{1,3 *}$, Munasib Khan ${ }^{2}$, Ishfaq Ali \\ Bukhari ${ }^{4}$, Anwarul Hassan Gilani ${ }^{1}$ \\ ${ }^{1}$ Natural Product Research Division, Department of Biological and Biomedical Sciences, Aga Khan University, Karachi, \\ ${ }^{2}$ Department of Pharmacy, University of Malakand, KPK, ${ }^{3}$ Department of Pharmaceutical Sciences, Government College \\ University, Faisalabad, Pakistan, ${ }^{4}$ Department of Pharmacology College of Medicine, King Saud University, Riyadh, Saudi \\ Arabia \\ ${ }^{*}$ For correspondence: Email: malikhassan.mehmood@gmail.com; Tel: (+92 21) 34930051 ext 4465; Fax: (+92 21) 34934294
}

\begin{abstract}
Purpose: To determine the mechanism of vasorelaxant effect of 1-trifluoromethoxyphenyl - 3 -(1propiony/piperidin-4-yl) urea (TPPU) in cardiovascular diseases, including hypertension.

Methods: Isolated rat thoracic aortic tissue preparations were mounted in an organ bath set up integrated with isometric transducer and a Power Lab assembly. TPPU (0.3-100 $\mu \mathrm{M})$ was tested for vasorelaxant effect against low $K^{+}(25 \mathrm{mM})$ and high $K^{+}(80 \mathrm{mM})$-induced contractions and its mechanism was determined in the presence of different antagonists (glibenclamide, 4- aminopyridine and tetraethyl ammonium).

Results: In rat aortic preparations, TPPU showed a concentration-dependent $(0.3-100 \mu \mathrm{M})$ and significant $(p<0.001)$ inhibition of low $K^{+}$induced contractions with complete inhibition obtained at 100 $\mu M$. TPPU produced significant $(p<0.05)$ inhibition of high $K^{+}$induced contractions with maximum relaxation of $15.36 \pm 1.95 \%$ and $15.85 \pm 3.35 \%$ at 30 and $100 \mu \mathrm{M}$, respectively. Glibenclamide $(G b, 10 \mu M)$ pretreatment partially inhibited the vasorelaxant effect of TPPU against low $K^{+}$in a concentration range of 1 - $30 \mu \mathrm{M}$. 4-Aminopyridine (4-AP, $1 \mathrm{mM}$ ) and tetraethyl ammonium (TEA, 10 $m M)$, markedly inhibited the vasorelexant effect of TPPU against low $K^{+}$induced contractions with maximum relaxation of $20.09 \pm 2.40$ and $21.67 \pm 0.88 \%$, respectively, at $100 \mu \mathrm{M}$.

Conclusion: TPPU possesses marked vasorelaxant properties which provides sound pharmacological evidence for its use as a potential drug candidate in the management of hypertension.
\end{abstract}

Keywords: 1-Trifluoromethoxyphenyl-3-(1-propionylpiperidin-4-yl) urea, Hypertension, vasodilator, $K^{+}$ channel activation, $\mathrm{Ca}^{+}$- channel antagonist

This is an Open Access article that uses a funding model which does not charge readers or their institutions for access and distributed under the terms of the Creative Commons Attribution License (http://creativecommons.org/licenses/by/4.0) and the Budapest Open Access Initiative (http://www.budapestopenaccessinitiative.org/read), which permit unrestricted use, distribution, and reproduction in any medium, provided the original work is properly credited.

Tropical Journal of Pharmaceutical Research is indexed by Science Citation Index (SciSearch), Scopus, International Pharmaceutical Abstract, Chemical Abstracts, Embase, Index Copernicus, EBSCO, African Index Medicus, JournalSeek, Journal Citation Reports/Science Edition, Directory of Open Access Journals (DOAJ), African Journal Online, Bioline International, Open-J-Gate and Pharmacy Abstracts

\section{INTRODUCTION}

Soluble epoxide hydrolase (sEH) has been a recent focus of research, is an indigenous enzyme which metabolizes epoxyeicosatrienoic acids (EETs) to functionally less active produces, the dihydroxyeicosatrienoic acids DHETs [1]. In endothelial cells, cytochrome P450 
epoxygenase metabolizes arachidonic acid to produce EET. EETs are well known for diverse biological activities including vasodilation, antiinflammatory, platelet aggregation inhibitory, analgesic and cardioprotection [2,3].

sEH is an indigenous enzyme which transforms EETs to inactive dihydroxyeicosatrienoic acids DHETs [2]. The potential biological activities of DHETs such as vasodilatation and antiinflammatory effects are less compared to EETs [4]. sEH is widely distributed in intestine, liver, kidney, vascular smooth muscles, neuronal cells and astrocytes [5]. Inhibition of sEH enzyme activity causes elevated levels of EETs in biological fluid and tissues, thus promoting beneficial pharmacological actions of EETs in the body. These findings suggest that sEH inhibition could be a potential therapeutic target for cardiovascular disease and pain and inflammatory conditions [6].

Inhibition of sEH enzyme prevents biodegradation of EETs and enhances their beneficial actions. Growing body of literature revealed that deletion of $\mathrm{sEH}$ or over activity of CYP epoxygenase lowered blood pressure in animal model of hypertension [7]. Large number of studies have revealed anti-inflammatory, vasodilator, antihypertensive, cardiac and renal protective effects of sEH inhibitors $[6,8,9]$.

1-Trifluoromethoxyphenyl-3-(1-propionylpiperidin -4-yl) urea (TPPU) is novel among the sEH inhibitors with relatively better pharmacokinetic and biological activity profile [10]. Human and animals studies have also shown TPPU as a potent inhibiter of sEH [11]. Though TPPU has been widely studied for its diverse biological activities, however, its vasorelaxant effect in intact vascular tissues is yet to be explored. The present study explored the possible vasodilator activity of TPPU, mediated predominantly through activation of voltage-dependent $\mathrm{K}^{+}$ channels, which may explain the potential therapeutic role of this compound in the management of hypertension.

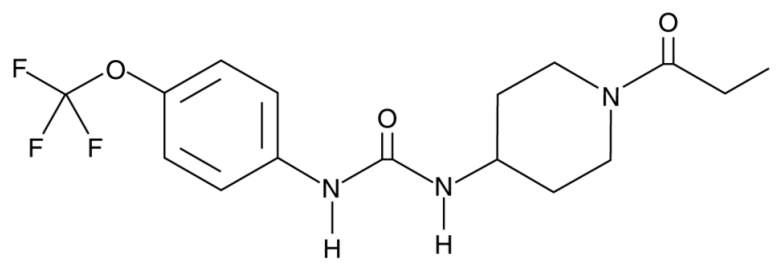

Figure 1: Chemical structure of soluble epoxide hydrolase inhibitor, TPPU

\section{EXPERIMENTAL}

\section{Chemicals}

Different $\mathrm{K}^{+}$channel antagonists, tetraethyl ammonium (TEA), 4-aminopyridine (4-AP) and glibenclamide $(\mathrm{Gb})$ were acquired from Sigma Chemicals Company (St Louis, MO, USA). TPPU was procured from Synthia laboratories Davis, California, USA. Other chemicals used in the study such as Potassium chloride, calcium chloride, glucose, magnesium sulphate, potassium dihydrogen phosphate, sodium bicarbonate and sodium chloride were obtained from E. Merck, Darmstadt, Germany. All chemicals used were of the analytical grade.

EXPERIMENTAL ANIMALS

Sprague-Dawley rats of either sex and weighing $180-200 \mathrm{~g}$ were maintained at the Animal House facility of Aga Khan University Medical College at $23-25^{\circ} \mathrm{C}$. Animals had free access to tap water, ad libitum. Animal were provided standard diet which consists of $(\mathrm{g} / \mathrm{kg})$ : flour 380 , fiber 380 , molasses $12, \mathrm{NaCl} 5.8$, nutrivet L. 2.5, powdered milk 150, vegetable oil 38, potassium metabisulfate 1.2 and fish meal 170. Water was withdrawn from rats for $12-14 \mathrm{~h}$ prior to anesthesia. The animals were euthanized following deep anesthesia with isoflurane (2 - 5 $\% \mathrm{v} / \mathrm{w}$ ) by inhalation in a closed chamber. After the achievement of deep anesthesia that was confirmed by absence of touch and corneal reflexes of the animals, thoracotomy was performed followed by cardiac puncture/heart excision to euthanize the animals.

Experiments were conducted and compiled to the guidelines of Institutional ethics committee and the Institute of Laboratory Animal Resources, Commission on Life Sciences, National Research Council (National Research Council, 1996) [12]. This research work was the part of the PhD dissertation of Mr. Shafiq Ali Shah, which was reviewed and approved by the Board of Studies and Research at University of Malakand, KPK, Pakistan and Aga Khan University Medical College Karachi Pakistan, with approval no. 60-ECACU-BBS-15.

\section{Animal studies}

Rats were euthanized after they were fully anesthetized with isoflurane by inhalation. Isoflurane was used 2-5\% v/w, till achievement of deep anesthesia. Once deep anesthesia was achieved and confirmed by absence of touch and corneal reflexes, thoracotomy was performed followed by cardiac puncture/heart excision to euthanize the animals. Afterwards, the thoracic 
aorta was isolated, cleaned of fatty tissues, cut into small rings and mounted individually in a tissue bath $(5 \mathrm{~mL})$ filled with Kreb's solution at 37 ${ }^{\circ} \mathrm{C}$ and aerated with carbogen [13]. A resting tension of $2 \mathrm{~g}$ was gradually applied to mounted aortic tissue preparation. The tissues were initially incubated for $30 \mathrm{~min}$ and finally equilibrated for $1 \mathrm{~h}$ prior to addition of any chemical agent. $\mathrm{K}^{+}$at low $(25 \mathrm{mM})$ and high (80 $\mathrm{mM}$ ) concentration was used to stabilize the respective tissue preparations until achievement of constant responses usually after $2-3$ times application followed by washing of the tissue with fresh Kreb's solution [14]. After stabilization state, low and high $\mathrm{K}^{+}$was administered to the tissue to induce sustained contractions, respectively. The relaxant effect of TPPU at 0.1 $100 \mu \mathrm{M}$ was assessed against low and high $\mathrm{K}^{+}$induced contractions, respectively. Isometric responses of the vessels were measured employing isometric transducer 50-7996 (Harvard Apparatus, Holliston, MA, USA), connected to PowerLab assembly.

To explore the participation of $\mathrm{K}^{+}$channel opening and/or $\mathrm{Ca}^{++}$channel antagonist properties [15], the vasorelexant effect of TPPU was further studied against low $\mathrm{K}^{+}(25 \mathrm{mM})$ and high $\mathrm{K}^{+}(80 \mathrm{mM})$-induced contractions, respectively. After achieving sustained contractions of vessels to $\mathrm{K}^{+}$, TPPU $(0.1-100$ $\mu \mathrm{M})$ was added in a cumulative fashion to the vessels to obtain its concentration-dependent inhibitory responses. The relaxation of the tissue preparation was expressed as percentage of the control contraction mediated by $\mathrm{K}^{+}$.

To characterize and confirm the type of $\mathrm{K}^{+}$channels involved in the vasodilating effect, the inhibitory effect of TPPU was reproduced in the aortic preparation pretreated with glibenclamide (Gb, $10 \mu \mathrm{M})$, an ATP-dependent $\mathrm{K}^{+}$channel antagonist [16], tetraethyl ammonium (TEA, 10 $\mathrm{mM})$, a nonselective antagonist of the $\mathrm{K}^{+}$ channels [17] and 4 - aminopyridine (4-AP, 1 $\mathrm{mM})$, a voltage-dependent $\mathrm{K}^{+}$channel blocker add [14].

\section{Statistical analysis}

Data is presented as mean \pm standard error of mean (s.e.m, $n=4-6$ ) and the median effective concentrations $\left(\mathrm{EC}_{50}\right)$ with $95 \%$ confidence intervals $(\mathrm{Cl})$. Data was considered statistically significant at $p<0.05$. The inhibitory effects of various treatments were statistically analyzed by non-linear regression employing GraphPad program (GraphPad, San Diego, CA, USA).

\section{RESULTS}

\section{Vasodilating effect of TPPU in isolated rat vascular tissues}

When tested on isolated rat aortic tissue, TPPU caused significant $(p<0.001)$ inhibition of low $\mathrm{K}^{+}$-induced contractions in a concentration dependent manner with an $\mathrm{EC}_{50}$ value of 6.72 $\mu \mathrm{M}(6.32-7.02,95 \% \mathrm{Cl}, \mathrm{n}=4)$, while it has produced complete inhibition (100\% relaxation) at highest tested concentration of $100 \mu \mathrm{M}$ (Figure 2). TPPU produced mild but significant $(p<0.05)$ relaxation of high $\mathrm{K}^{+}(80 \mathrm{mM})$-induced contractions with resultant values of $15.36 \pm$ 1.95and $15.85 \pm 3.35 \%$ at higher test concentrations of 30 and $100 \mu \mathrm{M}$, respectively (Figure 2).

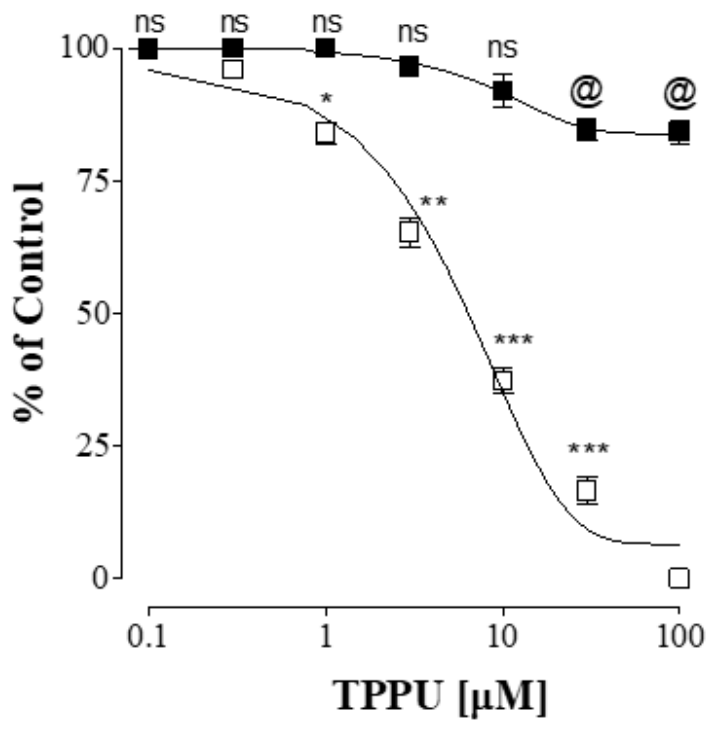

Figure 2. Inhibitory effect of TPPU on "ם" low $\mathrm{K}^{+}(25$ $\mathrm{mM})$ and " $\square$ "high $\mathrm{K}^{+}(80 \mathrm{mM})$-induced contractions in isolated rat aortic rings. Values shown are mean \pm S.E.M, $n=4-6$. "ns" represents non-significant, * ${ }^{@} p<$ $0.05, * * p<0.0, * \star * p<0.001$, $*$ shows comparison of the relaxant effect of TPPU on low $\mathrm{K}^{+}(25 \mathrm{mM})$-induced contractions vs. $100 \%$ control contractile response in that tissue. @ shows comparison of the relaxant effect of TPPU on high $\mathrm{K}^{+}(80 \mathrm{mM})$-induced contractions vs. $100 \%$ control contractile response in that tissue and ns $=$ non-significant

\section{Insight into mechanisms mediating vasodilating effect of TPPU}

To explore the subtype of $\mathrm{K}^{+}$channels involved in the observed vasodilator effect of TPPU, the tissues were pre-incubated with different $\mathrm{K}^{+}$ channel blockers. As shown in Figure 3 pretreatment of tissue with 4-aminopyridine (4 - AP, $1 \mathrm{mM}$ ), suppressed the relaxant effect of TPPU against low $\mathrm{K}^{+}$-induced contractions $(p<0.001)$ with remaining resultant relaxation of $12.9 \pm 2.46$ 
$\%(n=5)$ at $100 \mu \mathrm{M}$ compared to control vessels showing $100 \%$ relaxation in the absence of 4 AP observed at the same concentration. Similarly pretreatment of blood vessels with TEA (10 mM) caused significant $(p<0.001)$ attenuation of the relaxant effect of TPPU against low $\mathrm{K}^{+}$induced contractions with maximum relaxation of $13.5 \pm$ $3.50 \%$ versus $100 \%$ in control vessels in the absence of TEA (Figure 3). Pre-incubation of the blood vessels with glibenclamide $(10 \mu \mathrm{M})$ caused partial $(p<0.01)$ antagonism of the inhibitory effect of TPPU (Figure 3).

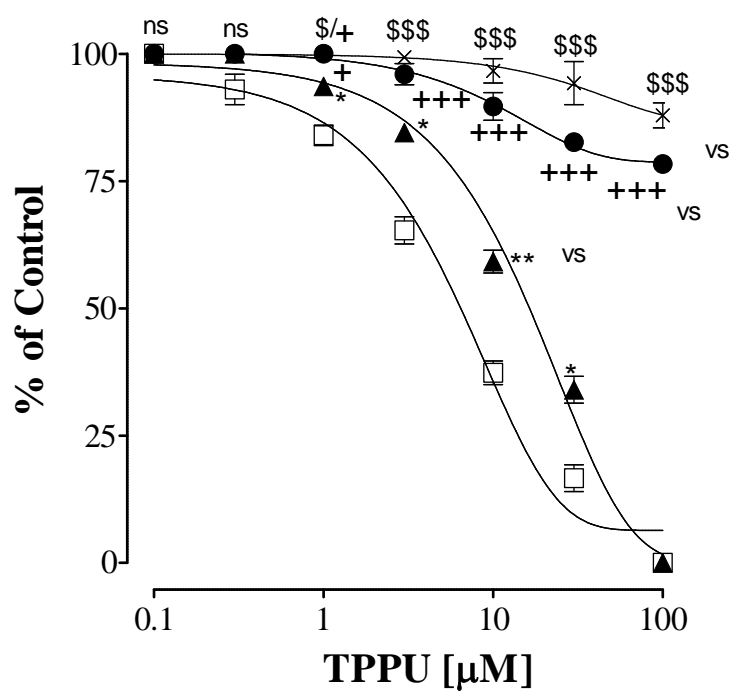

Figure 3. Inhibitory effect of TPPU on " $\square$ " low $\mathrm{K}^{+}$induced contractions in the absence and presence of

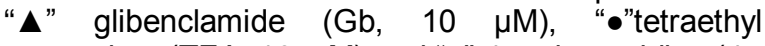
ammonium (TEA, $10 \mathrm{mM}$ ) and " $x$ " 4-aminopyridine (4 AP, $1 \mathrm{mM}$ ) in isolated rat aortic preparations. Values shown are mean \pm S.E.M, $n=4-6$. "ns" represents non-significant, $* /{ }^{+} p<0.05,{ }^{* *} /{ }^{++} \$ \$ p<0.01,\left.{ }^{+++}\right|^{\$ \$ \$} p<$ 0.001 , "*shows comparison of the relaxant effect of TPPU on low $\mathrm{K}^{+}(25 \mathrm{mM})$-induced in the presence vs. absence of Gb. "+" shows comparison of the relaxant effect of TPPU on low $\mathrm{K}^{+}(25 \mathrm{mM})$-induced in the presence vs. absence of TEA. "\$"shows comparison of the relaxant effect of TPPU on low $\mathrm{K}^{+}(25 \mathrm{mM})$-induced in the presence vs. absence of 4-AP

\section{DISCUSSION}

Recently TPPU has got much research attention for its efficacy as a potential therapeutic agent in cardiovascular disorders [18]. It has been shown to have antihypertensive effects by enhancing EETs level in the body via sEH inhibition. EETs are well recognized for their potent vasodilator effect.

The objective of this investigation was to explore the vasodilatory effect of TPPU and its possible mechanism in isolated rat aortic preparations. Previous studies have shown that vasodilator response of vessel is usually mediated through $\mathrm{K}^{+}$channel opening or $\mathrm{Ca}^{++}$channel blockade [15]. In order to characterize, whether the vasorelaxant effect of TPPU was mediated via similar pathways, its relaxant efficacy was tested against low $\mathrm{K}^{+}(25 \mathrm{mM})$ and high $\mathrm{K}^{+}(80 \mathrm{mM})$-induced contractions [19]. Interestingly, TPPU caused statistically significant $(p<0.001)$ and dose dependent inhibition of low $\mathrm{K}^{+}$-induced contractions with partial but significant $(p<0.05)$ inhibition against high $\mathrm{K}^{+}$-induced contractions only at 30 and $100 \mu \mathrm{M}$. The efficacy of TPPU against low $\mathrm{K}^{+}(25 \mathrm{mM})$-induced contractions suggesting $\mathrm{K}^{+}$channel opening activity of this compound [20]. It has been shown that compounds that selectively inhibit the low $\mathrm{K}^{+}(<$ $30 \mathrm{mM}$ ) induced contractions are considered $\mathrm{K}^{+}$ channel opener, while $\mathrm{Ca}^{++}$channel blockers are efficacious against both low and high $\mathrm{K}^{+}$-induced contractions [13, 21].

To elucidate the type of $\mathrm{K}^{+}$channels implicated in the vasorelaxant activity of TPPU, its effect was assessed against low $\mathrm{K}^{+}$-induced contraction in tissue pretreated with glibenclamide, a ATPdependent $\mathrm{K}^{+}\left(\mathrm{K}_{\mathrm{ATP}}\right)$ channels antagonist [16], TEA, a non-specific $\mathrm{K}^{+}$channel blocker [17] and 4-Aminopyridine, a voltage dependent $\mathrm{K}^{+}$ channels blocker [22]. Glibenclamide had partial inhibitory influence, while 4-AP and TEA caused marked inhibition of low $\mathrm{K}^{+}$-induced contractions suggesting that the vasorelaxant effect of TPPU is most likely mediated via activation voltagedependent $\mathrm{K}^{+}$channels ( $\mathrm{Kv}$ channels) and nonspecific $\mathrm{K}^{+}$channels. Moreover, these findings indicate the additional role of $\mathrm{K}_{\text {ATP }}$ channel activation and a weak $\mathrm{Ca}^{++}$antagonist-like effect [23] as possible vasorelaxant mechanism(s) of TPPU in part, though additional mechanism(s) cannot be ruled out.

Among varied types of $\mathrm{K}^{+}$channels, $\mathrm{Kv}$ neutralize the depolarization of the membrane potential via $\mathrm{K}^{+}$efflux [17]. Studies have also expressed $\mathrm{Kv}$ channels in aortic smooth muscles [24]. $\mathrm{K}^{+}$channel openers are potential new class of drugs with diverse therapeutic potential in hypertension, asthma, and gastrointestinal problems [25]. These compounds cause membrane hyperpolarization by opening $\mathrm{K}^{+}$ channels and increase in $\mathrm{K}^{+}$efflux, decreasing intracellular free $\mathrm{Ca}^{++}$leading to smooth muscle relaxation [17].

In conclusion, this study demonstrates that TPPU possesses profound vasorelaxant properties. These findings provide sound evidence for TPPU as a potential antihypertensive agent. Future studies are warranted to explore the mechanism 
of TPPU as potential vasodilator agent in the management of cardiovascular disorders.

\section{DECLARATIONS}

\section{Acknowledgement}

This research was supported by Deanship of Scientific Research, King Saud University, Riyadh, Kingdom of Saudi Arabia. The authors acknowledge the support and resources provided to Dr. Malik Hassan Mehmood from the Department of Biological and Biomedical Sciences, The Aga Khan University.

\section{Conflict of interest}

The authors declare that they have no competing interests with regard to this work.

\section{Authors' contributions}

We declare that this work was done by the authors named in this article and all liabilities pertaining to claims relating to the content of this article will be borne by the authors. Malik Hassan Mehmood and Ishfaq Ali Bukhari Ishfaq designed the project, Malik Hassan Mehmood and Anwarul Hassan Gilani supervised the study and drafted final manuscript. Shafiq Ali Shah carried out literature search, experimental work and data analysis. Anwar-ul-Hassan Gilani and Munasib Khan supported in data analysis and review of the manuscript. All authors reviewed and approved the final manuscript for publication.

\section{REFERENCES}

1. Zeldin DC. Epoxygenase pathways of arachidonic acid metabolism. J Biol Chem 2001; 276(39): 36059-36062.

2. Bukhari IA, Gauthier KM, Jagadeesh SG, Sangras B, Falck J, Campbell WB. 14, 15-Dihydroxy-eicosa-5 (Z)enoic acid selectively inhibits 14, 15-epoxyeicosatrienoic acid-induced relaxations in bovine coronary arteries. $J$ Pharmacol Exp Ther 2011; 336(1): 47-55.

3. Morisseau C, Hammock BD. Impact of soluble epoxide hydrolase and epoxyeicosanoids on human health. Annual review of pharmacology and toxicology 2013; 53: 37-58.

4. Imig JD, Hammock BD. Soluble epoxide hydrolase as a therapeutic target for cardiovascular diseases. Nat Rev Drug Discov 2009; 8(10): 794-805.

5. Newman JW, Morisseau C, Hammock BD. Epoxide hydrolases: their roles and interactions with lipid metabolism. Prog Lipid Res 2005; 44(1): 1-51.

6. Ingraham $R$, Gless $R$, Lo $H$. Soluble epoxide hydrolase inhibitors and their potential for treatment of multiple pathologic conditions. Curr Med Chem 2011; 18(4): 587603.

7. Capdevila J, Falck J, Imig J, Roles of the cytochrome P450 arachidonic acid monooxygenases in the control of systemic blood pressure and experimental hypertension. Kidney Int 2007; 72(6): 683-689.

8. Imig JD, Walsh KA, Khan MAH, Nagasawa T, Shaw MC, Shaw SM, Hammock BD. Soluble epoxide hydrolase inhibition and peroxisome proliferator activated receptor $y$ agonist improve vascular function and decrease renal injury in hypertensive obese rats. Exp Biol Med 2012; 237(12): 1402-1412.

9. Bukhari IA, Shah AJ, Gauthier KM, Walsh KA, Koduru SR, Imig JD, Falck JR, Campbell WB. 11, 12, 20 Trihydroxy-eicosa-8 (Z)-enoic acid: a selective inhibitor of 11, 12-EET-induced relaxations of bovine coronary and rat mesenteric arteries. Am J Physiol Heart Circ Physiol 2012; 302(8): 1574-1583.

10. Liu JY, Lin YP, Qiu H, Morisseau C, Rose TE, Hwang $\mathrm{SH}$, Chiamvimonvat $\mathrm{N}$, Hammock BD. Substituted phenyl groups improve the pharmacokinetic profile and anti-inflammatory effect of urea-based soluble epoxide hydrolase inhibitors in murine models. Eur J Pharm Sci 2013; 48(4): 619-627.

11. Sasso O, Wagner K, Morisseau C, Inceoglu B, Hammock $B D$, Piomelli D. Peripheral FAAH and soluble epoxide hydrolase inhibitors are synergistically antinociceptive. Pharmacol Res 2015; 97: 7-15.

12. Council NR. Guide for the care and use of laboratory animals. Institute of Laboratory Animal Resources, Commission on Life Sciences. National Academy of Sciences: Washington, DC; 1996.31-36.

13. Khan M, Khan AU, Rehman NU, Gilani AH. Blood pressure lowering, vasodilator and cardiac-modulatory potential of Carum roxburghianum seed extract. Clin Exp Hypertens 2015; 37(2): 102-107.

14. Gilani AH, Rehman NU, Khan A, Alkharfy KM. Studies on Bronchodilator Activity of Salvia officinalis (Sage): Possible Involvement of $K_{+}$Channel Activation and Phosphodiesterase Inhibition. Phytother Res 2015; 29(9): 1323-1329.

15. Gilani AH, Khan AU, Ghayur MN, Ali SF, Herzig JW. Antispasmodic Effects of Rooibos Tea (Aspalathus linearis) is Mediated Predominantly through K+-Channel Activation. Basic Clin Pharmacol Toxicol 2006; 99(5): 365-373.

16. Franck $H$, Puschmann A, Schusdziarra V, Allescher $H D$. Functional evidence for a glibenclamide-sensitive $K_{+}$ channel in rat ileal smooth muscle. Eur $J$ Pharmacol 1994; 271(2-3): 379-386.

17. Cook NS. The pharmacology of potassium channels and their therapeutic potential. Trends Pharmacol Sci 1988; 9(1): 21-28.

18. Guo Y, Luo F, Zhang $X$, Chen J, Shen L, Zhu Y, Xu D. TPPU enhanced exercise-induced epoxyeicosatrienoic acid concentrations to exert cardioprotection in mice after myocardial infarction. J Cell Mol Med 2018; 22(3): 1489-1500.

Trop J Pharm Res, June 2018; 17(6): 1023 
19. Khan AU, Gilani AH. Selective bronchodilatory effect of Rooibos tea (Aspalathus linearis) and its flavonoid, chrysoeriol. European J Nutrition 2006; 45(8): 463-473.

20. Khan A, AlKharfy KM, Gilani AH. Antidiarrheal and antispasmodic activities of Salvia officinalis are mediated through activation of $K+$ channels. Bangladesh J Pharmacol 2011; 6(2): 111-116.

21. Hamilton T, Weir SW, Weston A. Comparison of the effects of BRL 34915 and verapamil on electrical and mechanical activity in rat portal vein. Br J Pharmacol 1986; 88(1): 103-111.

22. Okabe K, Kitamura K, Kuriyama H. Features of 4aminopyridine sensitive outward current observed in single smooth muscle cells from the rabbit pulmonary artery. Pflugers Arch 1987; 409(6): 561-568.
23. Imran I, Hussain L, Zia-UI-Haq M, Janbaz KH, Gilani $A H$, De Feo V. Gastrointestinal and respiratory activities of Acacia leucophloea. J Ethnopharmacol 2011; 138(3): 676-682.

24. Li H, Kim HW, Shin SE, Seo MS, An JR, Ha KS, Han ET, Hong $S H$, Firth $A L$, Choi $I W$ et al. The vasorelaxant effect of mitiglinide via activation of voltage-dependent $K$ (+) channels and SERCA pump in aortic smooth muscle. Life sciences 2017; 188: 1-9.

25. Lenz T, Wagner G. Potential role of potassium channel openers for the treatment of cardiovascular disease. Hypertension: Pathophysiology, diagnosis and management. Laragh JH, Brenner BM (eds). New York, Raven Press 1995: 2953-2968. 